\title{
Understanding the need to be loved
}

Previously published at www.cmaj.ca

Sweet Sorrow: Love, Loss and Attachment in Human Life

Alan B. Eppel

Karnac Books; 2009.

$\mathrm{S}$ ociety is obsessed with love and we invest substantially in promoting healthy relationships in family and community. No surprise there, according to psychiatrist Dr. Alan B. Eppel, because the drive to attach is fundamental to human nature.

But we don't always do a very good job of it. And, Eppel warns, the Internet age could be making things worse with superficial and potentially false digital attachments. These days, for example, people use online services to search for intimacy, sexual satisfaction and social affiliations. They create instant connections with text messaging. Indeed, many people are becoming skilled marketers of their images, personalities and life goals in a desperate bid to attach to others.

People need to develop deeper and more genuine connections or face the public and personal health consequences of attachment disorders, says Eppel, the director of Community Psychiatric Services at St. Joseph's Hospital and an associate clinical professor at McMaster University in Hamilton, Ont.

Health care providers are confronted with attachment problems every day. Family health issues, such as parentchild bonding or partnership-marriage tensions or failures, are widespread in Canada. Personal health issues, such as low self-esteem, loneliness and isolation, are tragically commonplace, as are community health issues, such as disengagement, poverty and homelessness. The bottom line is that attachment

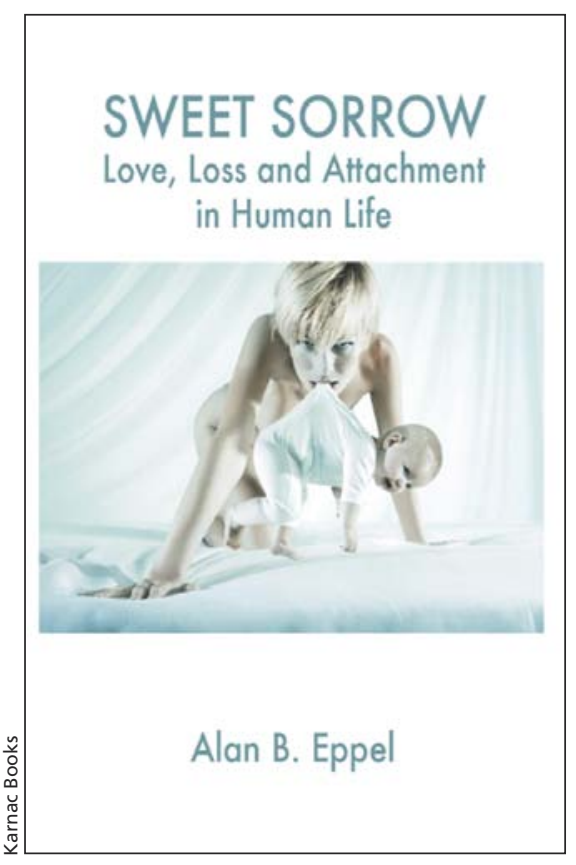

is a substantial issue for all of us in health. And the social costs are huge: mental illness, abuse and violence, sexually transmitted diseases, suicide and - at an extreme - sociopathy, criminality and radicalism.

In Sweet Sorrow: Love, Loss and Attachment in Human Life, Eppel tries to clarify the complex topic of human relationships through theory, clinical case examples and references to art and music. He offers 11 core propositions to explain love and loss:

- The drive to attach is fundamental to human nature.

- Striving for attachment is the strongest motivator of behaviour.

- Identity is formed from interpersonal interaction.

- Mood is the bedrock of identity and the sense of self.

- Psychiatric disorders reflect and affect the expression of love and loss.

- Disorders of sexual desire comprise the inability to maintain healthy attachments simultaneously with sexual intercourse.

- The intensity of loss and grief is directly proportional to the intensity of the attachment bond.

- The death instinct exerts itself when attachments are lost.

- Time is relative: Acceleration of time is associated with alienation; expansion of time is associated with authentic human experience.

- The need for meaning is fundamental to human nature.

- The drive to attach gives rise to the strongest sense of meaning in human interaction.

Eppel also illustrates three components of mature love - emotional intimacy, sexual passion and interpersonal commitment - and identifies "love disorders," including the inability to fall in love, to remain in love, to fall out of love and to feel love from another. Love is a powerful tool in health; anything we can do as health providers to promote its healthy emergence and vitality is critical to our work.

Readers passionate about social and psychological aspects of health and disease, working with marginalized or disadvantaged communities or engaged in mental health practice will enjoy this book. It would also be invaluable to psychiatry residents and other professional trainees interested in mental health and illness and community health. That said, it is also an excellent and accessible introduction to attachment theory for readers curious about their own attachments to others.

\section{Derek Puddester MD MEd \\ Director \\ Faculty Wellness Program \\ University of Ottawa \\ Ottawa, Ont.}

